\title{
Australia's mining productivity decline: Implications for MFP measurement
}

\author{
Simon Zheng and Harry Bloch \\ Curtin University \\ Australia
}

October 2012

\begin{abstract}
This paper investigates the mining sector's poor productivity performance as measured by the growth accounting formula for multifactor productivity (MFP) index during the recent mining boom in Australia. We provide an alternative measure of productivity growth by estimating a translog variable cost function, with parameters that separate productivity growth due to technical change from that due to the effects of returns to scale, capacity utilisation and natural resource inputs. The results show that the average MFP growth in Australian mining based on the dual cost-function measure of technical change is $2 \%$ over the sample period $1974-75$ to $2007-08$, rather than $-0.2 \%$ from the published index. The difference arises because declining natural resource inputs, the effects of capacity utilisation and returns to scale have all reduced the 'true' MFP growth.
\end{abstract}

JEL classifications: C32; L72; O40

\section{Acknowledgments}

We thank two anonymous referees, the Guest Editors and participants at the Asia Pacific Productivity Conference 2010 for helpful comments. All errors and omissions remain the responsibility of the authors. 


\section{Introduction}

Driven by the strong demand for mineral and energy products from the emerging economies, particularly China, global non-agricultural commodity prices have increased significantly since the early part of this millennium. According to the IMF's commodity price index, world metals and fuel prices in 2011 are more than 4 times higher than their levels in 2002. As a major commodity export country, Australia has experienced a strong surge in production, investment and employment in mining, including petroleum and natural gas extraction, as a result of this mining commodities boom.

The price increase that has benefited Australia during the mining boom has been exceptional, with average annual growth in Australian mining output prices of nearly $19.6 \%$ from 2002-03 to 2010-11. In comparison, the same price index recorded an annual increase of $0.1 \%$ on average between 1985-86 and 2001-02, a period before the mining boom. Yet, Australian mining has suffered from a persistent decline in multifactor productivity (MFP) every year between 2002-03 and 2010-11, with an average annual decline of 5.5\% according to the MFP index published by the Australian Bureau of Statistics (ABS) (ABS 2011), compared to an annual rise in MFP of 2.4\% between 1985-86 and 2001-02. The correlation coefficient between the index of the mining prices and the index of measured MFP is -0.65 . The negative relationship between the two is quite clear from Figure 1, particularly since the start of the recent mining boom. 
Figure 1: Australia's mining commodity prices and productivity performance

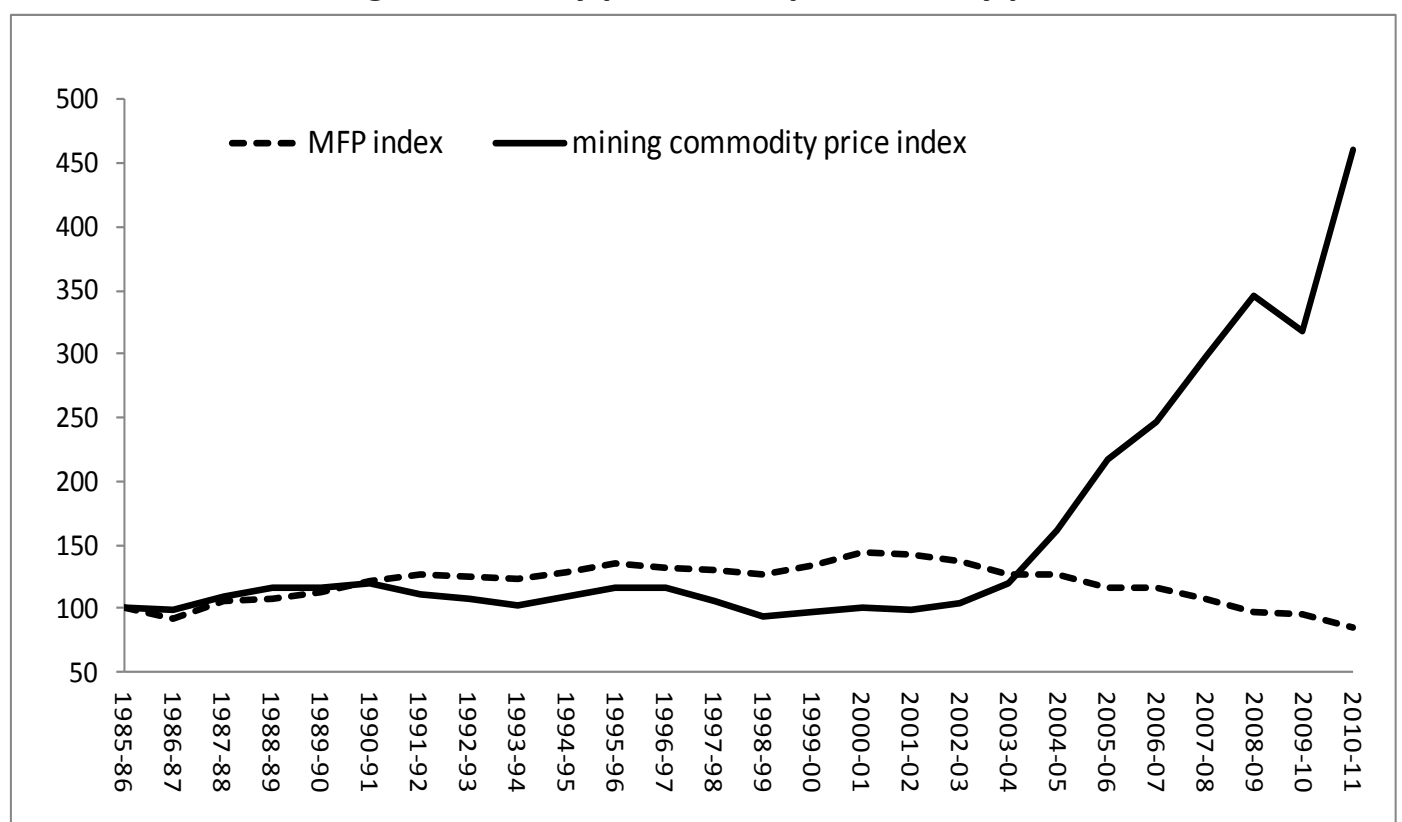

Data Source: the index of mining commodity prices is from the Reserve Bank of Australia and the MFP index from ABS Cat. No. 5260.0.55.002.

For the economy as a whole, MFP tends to be pro-cyclical, implying that MFP tends to be higher when the economy is in a boom phase, while it tends to be lower when the economy is in a contraction or recession period (OECD 2001). However, this empirical relationship cannot be carried over to the Australian mining industry. As shown in Figure 1, measured MFP in mining is in fact counter-cyclical - when the industry is booming as reflected by the price surge, and associated output increases, its productivity performance is deteriorating; and, to a lesser extent, measured productivity is increasing when there is a decline in output prices. ${ }^{1}$

Particularly important in explaining the difference in the cyclical behaviour of productivity between mining and the overall economy is the role of the natural resource input, which is an integral part of the mineral and energy production process (Topp et al. 2008). The natural resource input is the contribution of the mineral deposit in its natural state to the production

\footnotetext{
1 The counter-cyclical movement in mining sector productivity is not unique to Australia. Bloch (2010) discusses the parallels between Australia and Canada in cyclical movements of mining sector productivity.
} 
of mineral output. As with other inputs to production, the contribution of natural resource input is measured at the margin by the rise in output that results from using the deposit.

For mineral production from a non-renewable resource, using the deposit has the special meaning of resource depletion. Two cases can be distinguished. Hotelling (1931) shows a declining optimal extraction of a homogenous non-renewable natural resource over time. The contribution of the deposit does not change, but the reduced supply leads to a rising price over time. However, for a heterogeneous deposit, the most easily accessible and highest quality deposits are exploited first, followed by less-accessible or lower quality reserves. In the absence of the discovery of new deposits, more production leads to fewer easily accessible reserves, and greater amounts of labour, capital and intermediate inputs have to be used to maintain the same level of output with a given technology. Alternatively, lower quality deposits yield less mineral content per unit of ore mined. Thus, in the case of heterogeneous deposits, the contribution from the natural resource input decreases with depletion of the resource.

Natural resource inputs do not generally have a market price and they are difficult to quantify properly due to their imperfect relation to depletion. Consequently, they are usually left out from conventional MFP calculations. While missing inputs affect the measurement of MFP in other industries, the level of severity of this problem is likely to be much higher in mining due to the importance of natural resource inputs in production. In particular, measured productivity growth in mining is biased downward with depletion of the natural resource inputs and the move to lower quality or less accessible deposits.

The exclusion of natural resource inputs and the resulting effect on measured MFP in mining have been noted in the literature. Studies that note the problem and attempt to correct it by adjusting the growth accounting measures of MFP include Wedge (1973), Lasserre and Ouellette (1988) and Young (1991) for Canadian mining industries, as well as Topp, et al 
(2008) for Australian mining. More recently, Rodriguez and Arias (2008) estimate a variable cost function for Spanish coal mining that enables them to decompose the Solow residual, separating the effects of non-constant returns, capacity utilisation and resource depletion. Their results show that the depletion of the coal reserves lowers the measured MFP growth in Spanish coal mining by 1.3 percentage points per annum on average over the sample period. We follow Rodriguez and Arias in estimating a variable cost function for the Australian mining sector as the basis for decomposing measured MFP growth.

This paper attempts to further develop our understanding of mining productivity by using estimates for a variable cost function for Australian mining to analyse the recently observed decline in mining productivity. The next section discusses in more detail the issues for the mining sector associated with using the growth accounting methodology to measure productivity growth. Section 3 uses the duality relationship between production and cost functions to derive a relationship between the measured and 'true' MFP growth, which is then used to decompose the effects on the difference between measured and 'true' MFP. It identifies a strong effect from failing to account for natural resource inputs, and emphasises the dual role of returns to scale and capacity utilisation on MFP. Section 4 estimates a translog variable cost function that provides the parameter values for the various components in the decomposition formula, and it also presents the main empirical results. The last section concludes.

\section{Problems with conventional productivity measurement in mining}

There have been several attempts to adjust conventional measures of multifactor productivity growth to account for the missing resource input. Wedge (1973) uses an index of ore grades as a proxy for natural resource inputs to challenge conventional measures that show low 
productivity growth in Canadian mining and finds a much higher corrected rate of productivity growth. Lasserre and Ouellette (1988) include the resource input as an explicit factor in the mining production function and also use the changes in ore grade to approximate the changes in quality of the resource input. Young (1991) uses regression techniques to estimate the impact of ore grade and geological accessibility of a deposit (proxied by cumulative production) on measured MFP and finds evidence that lower ore grade and higher cumulative production (thus lower geological accessibility) reduce measured MFP in Canadian copper-mining firms.

Recently, a study by Topp et al. (2008) focuses exclusively on Australian mining productivity and the related measurement issues. The authors estimate a 'yield' index that aggregates the changes in ore grade, oil and gas flow rates and the ratio of saleable to raw coal. This is to capture the effect of resource depletion. An alternative capital input index is also calculated to allow for the long lead time from investment to forming the capital stock actually used in production. With these adjustments, the corrected annual MFP growth for Australian mining over the period from 1974-75 to $2007-8$ becomes $2.3 \%$. These results are very different from the measured MFP growth of $0.01 \%$ over the same period based on the conventional MFP calculations.

In addition to the various adjustments made for the measurement of mining inputs and output in the studies reviewed above, there are systematic weaknesses in the conventional MFP measure associated with the assumptions of competitive markets and long-run equilibrium. These assumptions allow us to derive the MFP index without estimating some form of a production function, because they imply that the cost share for each input is equal to the elasticity of output with respect to that input. Clearly, this is a practical benefit of applying the non-parametric growth accounting approach, which is used by most national statistical agencies in deriving their published MFP indexes. However, when the assumptions are 
strongly violated, the MFP estimates could contain errors large enough to misinform us about the true level and direction of MFP growth. The problem is further exacerbated by the missing resource inputs when estimating MFP for the mining industry, as discussed above.

With the assumptions of competitive markets and long-run equilibrium, the value of the marginal product of each input used in production is always equal to its price. This may be a reasonable assumption for certain inputs, such as labour and intermediate inputs, which can be adjusted relatively quickly. However, capital should be treated as a quasi-fixed input, as it is fixed in the short run, while flexible in the long run.

In the short run, the quasi-fixity of capital distorts the relationship between cost shares and the elasticity of output with respect to variable inputs. If output price rises (falls) from a level with long-run equilibrium, the price is above (below) average cost in the short run. The increases (decreases) in variable inputs to adjust to the new price level involve a decrease (increase) in marginal product and a decrease (increase) in the corresponding elasticity of output with respect to that input. MFP growth as calculated using cost shares as in the conventional growth accounting formula is therefore understated (overstated).

The level of output in the short run may also differ from that determined by the long-run equilibrium, and the firm or industry can operate below or above its optimal capacity that is unique to the long-run equilibrium. If the level of output produced by a firm or industry differs from the optimal, long-run level, productivity also differs from its optimal level. Thus, the capacity utilisation effect originating from the presence of quasi-fixed inputs in production is a potential source of error in measured MFP.

The extent to which the various factors mentioned above introduce error into measured MFP for Australian mining is an empirical question. Before attempting to answer this question in relation to Australia's mining industry, we need first to establish an analytic relationship 
between the 'true' and measured MFP. This amounts to decomposing measured MFP into the 'true' MFP component and various other components that capture the effects of nonconstant returns to scale, quasi-fixity of capital and natural resource inputs. ${ }^{2}$

\section{A dual measure of MFP for mining}

The cost function contains essentially the same information on technology that the production function does, as long as producers are at a cost-minimising equilibrium and facing fixed input prices. This is the property of duality in production economics (see, e.g. Morrison Paul, 1999). As will be seen, this approach can also reveal many important aspects of production that are not obvious if only the production function is used.

\subsection{Cost minimisation and the variable cost function}

In the short run, the firm is minimising the total costs under the constraint of fixed capital and fixed natural resource input. This short-run cost minimisation problem can be written as:

$$
\begin{aligned}
C(w, r, v, K, R, Y, t) & =G(w, K, R, Y, t)+r K+v R \\
& =\underset{L}{\operatorname{Min}}\{w L \quad \text { s.t. } Y=F(K, L, R, t), \text { and } K, R \text { given }\} \\
& +r K+v R
\end{aligned}
$$

where $C(w, r, v, K, R, Y, t)$ captures the total costs, $G(w, K, R, Y, t)$ is the variable cost function that minimises variable cost (labour cost in this case) subject to the production technology at the given level of fixed inputs in the short run; $K$ and $L$ are capital and labour input with user cost of capital $r$ and wage rate $w ; Y$ represents value added output, and $R$ is the (composite) natural resource input for which the firm pays the price, $v$. This price represents

\footnotetext{
${ }^{2}$ The effect of market power in the product market can also be incorporated in the decomposition formula. See Zheng and Bloch (2010) for such a treatment.
} 
the cost to firm for the use of one unit of resource inputs. However, unlike capital and other conventional inputs, the resource input does not generally have a market to determine its price.

$v$ can be thought of as the opportunity cost of using the resource input today rather than keeping it in situ for use in the future. Alternatively, one can think of the resource input costs as the firm's spending on maintaining or improving the current condition in the existing mines, the expenditure on exploration activities to discover new deposits, including the costs of acquiring licenses for exploration and also those costs associated with maintaining the mine sites and organising the production process to meet certain environmental standards. In equilibrium, firms equate this cost at the margin to the value of the contribution of the natural resource input to producing extra output. The empirical approximation for $v$ is discussed further in the next section where a variable cost function is estimated.

In the short run, both $K$ and $R$ are fixed, and $r$ is the aggregate rental price of capital or the user cost, which is determined by aggregation over the prices of different asset types. Thus, in our formulation of the cost minimisation problem, capital and resource inputs are treated symmetrically. The difference between these two variables lies only in their empirical contents and interpretations. Consequently, the decomposition formula has different form and interpretation from the one that treats the resource input as an unpaid input for which there is no cost incurred to the firm and only the shadow price can be estimated. ${ }^{3}$

The elasticity of total cost with respect to output can be written as the ratio of marginal to average cost,

\footnotetext{
${ }^{3}$ Estimation of the variable cost function incorporates the impact of the fixity of the quantity of capital and resource input in the short run, while in estimating a production function, the long-run impact of a change in quantity of these inputs may not be adequately captured. Morrison and Schwartz (1996) include public infrastructure as an unpaid input in the variable cost function to derive their productivity decomposition formula. Rodriguez and Arias (2008) treat the level of coal reserves in the same way as public infrastructure is treated in Morrison and Schwartz (1996).
} 


$$
\varepsilon_{C, Y} \equiv \frac{\partial C}{\partial Y} \frac{Y}{C}=\frac{\partial C / \partial Y}{C / Y}
$$

This elasticity is often used as an alternative measure of returns to scale (see, e.g. Diewert and Fox 2008). It measures the cost responsiveness to changes in output, which depends inversely on output's responsiveness to changes in factor inputs, the more direct measure of returns to scale.

Using the first-order condition associated with the cost minimisation problem, the elasticity of output with respect to labour $\varepsilon_{Y, L}$ can be written in terms of the share of labour in total $\operatorname{cost} S_{L} \equiv w L / C$, as

$$
\varepsilon_{Y, L}=\frac{S_{L}}{\varepsilon_{C, Y}}
$$

Similarly to the share of labour input in total cost, the shadow cost shares of capital and the resource inputs can be defined as

$$
S_{K}^{*} \equiv \frac{Z_{K} K}{C} \text { and } S_{R}^{*} \equiv \frac{Z_{R} R}{C}
$$

where $Z_{K}$ and $Z_{R}$ are the shadow price for capital and resource inputs, respectively. The result analogous to (3) can be obtained regarding the relationships between the elasticity of output with respect to these two inputs and the output elasticity of the short-run cost function, namely

$$
\begin{gathered}
\varepsilon_{Y, K}=\frac{S_{K}^{*}}{\varepsilon_{C, Y}} \\
\varepsilon_{Y, R}=\frac{S_{R}^{*}}{\varepsilon_{C, Y}}
\end{gathered}
$$




\subsection{The primal and dual measures of technical progress}

The rate of technological progress is defined as the rate of growth in output that follows the passage of time with factor inputs being held constant. The production function included in (1) thus gives rise to the following primal measure of MPF growth,

$$
\varepsilon_{Y, t} \equiv \frac{F_{t}}{Y}=\hat{Y}-\varepsilon_{Y, K} \hat{K}-\varepsilon_{Y, L} \hat{L}-\varepsilon_{Y, R} \hat{R}
$$

where $F_{t}=\partial F / \partial t$ and $\hat{X}$ denotes the rate of growth for variable $X$. Note that the production function used here includes the resource inputs, $R$, as is appropriate for mining. The conventional measure of MFP growth that corresponds to the production function in (1) is the Solow residual given by

$$
\hat{A}=\hat{Y}-S_{K} \hat{K}-S_{L} \hat{L}-S_{R} \hat{R}
$$

This gives an index of technical change that is equal to the measure of technical change, $\varepsilon_{Y, t}$ in (7) under the assumptions of perfectly competitive input and output markets and long-run equilibrium. As discussed previously, the advantage of using the index from (8) is that no explicit knowledge of the production function and elasticities are required to measure technical change. The disadvantage, as discussed in detail below, is that it is subject to error as a measure of technical change when the conditions of long-run competitive equilibrium are not fulfilled.

Both the primal and dual measures of technical change have been used widely in productivity analysis. The dual measure of technical change reflects the rate of cost reduction while holding the level of output and input prices constant. Relating to the short-run cost minimisation problem of (1), the dual measure is defined as,

$$
-\varepsilon_{C, t} \equiv-\frac{\partial C}{\partial t} \frac{1}{C}
$$


Ohta (1974) shows that

$$
-\varepsilon_{C, t}=\varepsilon_{C, Y} \varepsilon_{Y, t}
$$

Equation (10) indicates that the dual index of technical progress is related to the primal one through a measure of returns to scale. Under constant returns to scale, the two measures of technical progress become equal.

\subsection{Links between the measured and 'true' MFP growth}

The relationship between the dual rate of technical progress and the Solow residual, $\hat{A}$, as a measure of productivity growth is found from the equations above as follows

$$
-\varepsilon_{C, t}=\hat{A}+\left(\varepsilon_{C, Y}-1\right) \hat{Y}+\left(S_{K}-S_{K}^{*}\right) \hat{K}+\left(S_{R}-S_{R}^{*}\right) \hat{R}
$$

The MFP growth index that is often used by statistical offices, including the ABS, makes no allowance for the cost of using natural resources and can be expressed in the form of

$$
\hat{A}^{m}=\hat{Y}-\left(\frac{r^{m} K}{p Y}\right) \hat{K}-\left(\frac{w L}{p Y}\right) \hat{L}
$$

where $\hat{A}^{m}$ indicates the measured MFP growth index and $r^{m}=(p Y-w L) / K$. It is now straightforward to derive a relationship between the Solow residual measure, $\hat{A}$, and $\hat{A}^{m}$ as

$$
\hat{A}=\hat{A}^{m}+\left(\frac{w L}{C}-\frac{w L}{p Y}\right)(\hat{K}-\hat{L})+S_{R}(\hat{K}-\hat{R})
$$

Using (13) and (11), we obtain

$$
\begin{aligned}
\hat{A}^{m} & =-\varepsilon_{C, t}+\left(1-\varepsilon_{C, Y}\right)\left[\frac{S_{L}}{\varepsilon_{C, Y}}(\hat{K}-\hat{L})+\hat{Y}\right] \\
& +\left(S_{K}^{*}-S_{K}\right) \hat{K}+\left(S_{R}^{*}-S_{R}\right) \hat{R}+S_{R}(\hat{R}-\hat{K})
\end{aligned}
$$


The expression in (14) shows that the decomposition of measured MFP growth consists of five components. ${ }^{4}$ The first component $\left(-\varepsilon_{C, t}\right)$ can be regarded as the 'true' productivity growth. The second component reflects the effect of returns to scale. If constant returns to scale is assumed (i.e. $\varepsilon_{C, Y}=1$ ), this component drops out from (14). The third and fourth components capture the effect of capacity utilisation for physical capital and natural resources, respectively, as defined in Hulten (1986) and Berndt and Fuss (1986), which will be discussed further next. The last component captures the remaining effect of natural resource inputs or resource depletion on measured MFP.

Equation (14) also shows that resource inputs can potentially increase the gap between the measured and the 'true' MFP growth from two different sources. The last term in (14) reflects the missing input effect, as the use of resource inputs is not accounted for in conventional MFP measurement (remember that $S_{R}$ is the share of natural resource costs in a proper Solow residual, while the conventional MFP measure sets this to zero). The penultimate term is the capacity utilisation effect, which is due to the quasi-fixity of the resource inputs, similar to the conventional capital. In the short run, resource inputs are fixed, while in the long run they are variable through the effect of depletion from cumulative production and the (opposite) effect of discoveries of new deposits. If the level of resource inputs is variable in the short run, as with labour, the capacity utilisation effect from the resource inputs disappears, but the missing input effect still remains with depletion (a negative growth in $R$ ), leading to a measured productivity growth below the dual rate of technical change.

\footnotetext{
${ }^{4}$ For a more detailed derivation of this decomposition formula that includes the effect of market power, see Zheng and Bloch (2010).
} 


\subsection{The effects of capacity utilisation on measured MFP}

In the following discussion of capacity utilisation, the focus is placed on one of the quasifixed inputs, conventional physical capital, but the analysis can be carried over to the natural resource inputs.

From (14), if $S_{K}^{*}>S_{K}$, which is equivalent to $Z_{K}>r$, then the marginal contribution of physical capital is greater than its market price. Thus, the firm has incentives to invest in additional stock of capital. When the firm produces the output at a level that is greater than its long-run equilibrium level $\left(Y>Y^{*}\right)$, where $Y^{*}$ denotes the long-run equilibrium level of output, a greater quantity of variable inputs has to be applied to the quasi-fixed stock of capital in the short run. Thus, in this sense, the capacity is over-utilised. Under this situation, the physical capital earns a quasi-rent that exceeds the market price. This concept of capacity utilisation is due to Berndt and Fuss (1986), who define that the rate of capacity utilisation is greater (less) than unity, when $Y>Y^{*}$, or equivalently $Z_{K}>r$ or $S_{K}^{*}>S_{K}\left(Y<Y^{*}\right.$ or $Z_{K}<r$ or $\left.S_{K}^{*}<S_{K}\right)$.

The following diagram illustrates the effects of capacity utilisation on the measured productivity growth. 
Figure 2: Effects of capacity utilisation on measured MFP when the 'true' productivity growth is positive

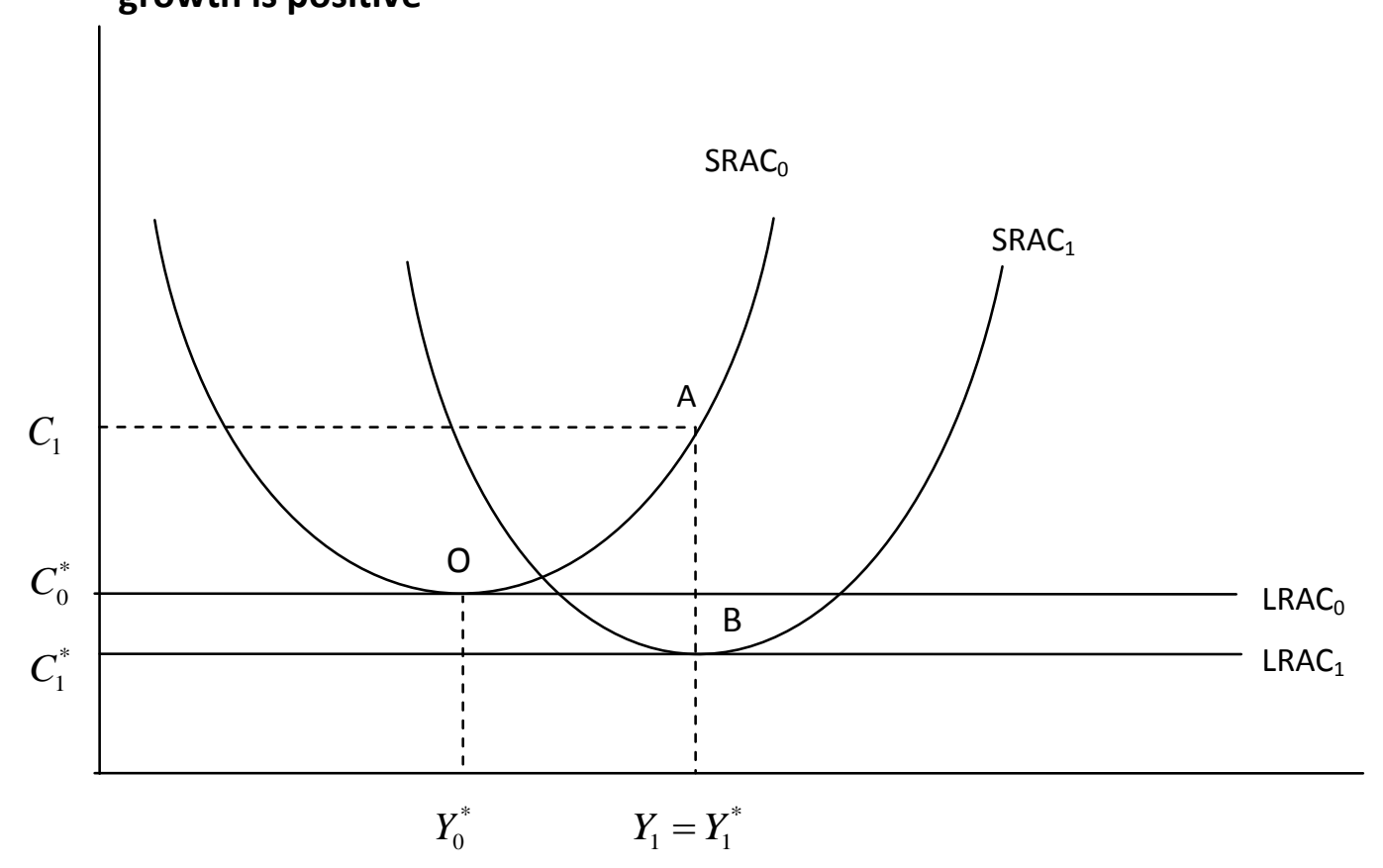

We assume that the firm operates under the conditions of constant returns to scale and constant input prices in the long run. This implies that the firm's long-run average cost function (LRAC) is a horizontal line as shown in Figure 2. As the input prices remain constant, vertical shifts in LRAC curves reflect the 'true' changes in MFP. The short-run average cost curves (SRAC) are U-shaped because capital is quasi-fixed in the short run. ${ }^{5}$ The position and shape of the SRAC curves are dependent on technology, output quantity, input prices and quantities. It is well known that each SRAC curve is tangent to the LRAC curve at an output level that is associated with the minimum level of short-run cost.

The initial equilibrium level of production and cost are at point $\mathrm{O}\left(C_{0}^{*} Y_{0}^{*}\right)$ where $\mathrm{SRAC}_{0}$ is tangent to $\mathrm{LRAC}_{0}$. Now suppose that under a demand-driven boom, the firm increases the level of production in period 1 to $Y_{1}$ with the increased average cost at $C_{1}$ on the initial

\footnotetext{
${ }^{5}$ The underlying short-run total cost is a cubic function of output.
} 
SRAC curve. Assume that $Y_{1}$ is also the new equilibrium level of output (i.e. $Y_{1}=Y_{1}^{*}$ ). Based on Berndt and Fuss (1986)'s notion of capacity utilisation as outlined above, at point $\mathrm{A}\left(C_{1} Y_{1}\right)$, the period 0 capacity is over utilised, as the level of output is above the initial longrun equilibrium level of production $Y_{0}^{*}$. This also implies that the shadow price of capital is greater than the market price, and the firm has incentives to invest in additional capital stock.

When the firm increases the stock of capital to the desired level in period 1, the SRAC curve shifts to the right to $\mathrm{SRAC}_{1}$. The average cost is decreased to the level where the new shortrun average cost curve $\left(\mathrm{SRAC}_{1}\right)$ is tangent to the new long-run average cost curve $\left(\mathrm{LRAC}_{1}\right)$ at point $\mathrm{B}\left(C_{1}^{*} Y_{1}^{*}\right)$, which is lower than point $\mathrm{O}\left(C_{0}^{*} Y_{0}^{*}\right)$ due to technological progress. This implies that at point $\mathrm{B}\left(C_{1}^{*} Y_{1}^{*}\right)$, the capacity is fully utilised in period 1 . Thus, the rate of capacity utilisation has to decrease moving from point A (a point associated with overutilised capacity) to point B.

If only the two data points $\mathrm{O}\left(C_{0}^{*} Y_{0}^{*}\right)$ and $\mathrm{A}\left(C_{1} Y_{1}\right)$ are observed in the two periods under the consideration, the traditional Solow residual measures MFP growth as the negative of the logarithm of $C_{1} / C_{0}^{*}$, which is negative, indicating a decline in productivity. But the true MFP growth should involve points $\mathrm{O}\left(C_{0}^{*} Y_{0}^{*}\right)$ and $\mathrm{B}\left(C_{1}^{*} Y_{1}^{*}\right)$, which is positive as the longrun average cost decreases $\left(C_{1}^{*}<C_{0}^{*}\right)$ over time. The 'true' measure of MFP growth, $-\varepsilon_{C, t}$ in (11) should also be positive in this case, as it is invariant to the short-run utilisation effect.

\section{Estimating a variable cost function}

The various components in the decomposition equation (14) can be measured by estimating a variable cost function. In practice, however, we are constrained by the available data that can be used for the estimation. Particularly, as discussed previously, the resource inputs contain 
many intangible factors that are difficult to quantify in a systematic fashion. As such, a proxy variable is used in econometric estimation in order to gain some quantitative insights into the impact of natural resource inputs on measured MFP.

As reviewed previously, Rodriguez and Arias (2008) use the level of coal reserves to control for the effect of resource depletion (i.e. the decline in natural resource inputs) in their estimation of the biases associated with the Solow residual for the Spanish coal industry. The study by Topp et al. (2008) constructs a yield index that is largely based on the ore grades for various minerals in the sub-sectors of Australian mining. This yield index is intended to capture the changes in the quality of the resource inputs.

Here, the part of productive capital stock in mining that is attributed to mineral and petroleum exploration is used as a proxy for the services derived from the stock of resource inputs. This amounts to separating the measure of mining capital services into two parts - one is the conventional physical capital stock similar to that used in other industries, ${ }^{6}$ the other part is accumulated only by the investment in mineral and petroleum exploration, which is unique to mining. This implies that the resource inputs used here are also subject to declining productivity over time, similar to depreciation on the conventional physical capital stock. ${ }^{7}$

Like proxy variables used in other studies, the calculated productive capital stock from mineral and petroleum exploration does not correspond strictly to a measure of resource inputs. While not all exploration activities result in discoveries of new deposits, they are a prerequisite for maintaining as well as enhancing the quality and quantity of resource inputs that are essential for mining production. More exploration activity can be seen as partly a

\footnotetext{
6 In mining, the physical capital items include computer software, computers, electrical and electronic equipment, industrial machinery and equipment, other plant and equipment, other transport equipment, road vehicles, non-dwelling construction, non-farm inventories and land.

${ }^{7}$ See OECD (2001) for a discussion of how the rate of depreciation is related to the age-price and the ageefficiency profiles.
} 
response to the decline in quantity and quality of mineral and petroleum reserves. ${ }^{8}$ Usefully, this proxy variable is directly available from the ABS and is based on the measurement framework that is consistent with that for the other variables used in this study. ${ }^{9}$

\subsection{The translog variable cost function}

The translog cost function is one of the popular choices of functional form in empirical production economics. Its broad applicability is largely due to its correspondence to a flexible underlying production technology that places minimum a priori restrictions. Recent applications of this functional form in the studies of mining industry include the work by Azzalini, et al. (2008) and Rodriguez and Arias (2008), where the latter employs a variable cost function. Various econometric issues associated with specifying and estimating a translog cost function are discussed extensively in Berndt (1991).

The variable cost function used in this study only contains one variable input, namely labour, while both capital and resource inputs are treated as fixed inputs in the short run. This is because value added is our output measure and our emphasis is on the short-run and long-run distinctions, as discussed above. This translog variable cost function is written as

$$
\begin{aligned}
\ln V C= & \beta_{0}+\beta_{w} \ln w+\beta_{Y} \ln Y+\beta_{R} \ln R+\beta_{K} \ln K \\
& +\frac{1}{2}\left[\beta_{w w}(\ln w)^{2}+\beta_{K K}(\ln K)^{2}+\beta_{R R}(\ln R)^{2}+\beta_{Y Y}(\ln Y)^{2}\right] \\
& +\beta_{K w} \ln K \ln w+\beta_{R w} \ln R \ln w+\beta_{K R} \ln K \ln R \\
& +\beta_{K Y} \ln K \ln Y+\beta_{R Y} \ln R \ln Y+\beta_{w Y} \ln w \ln Y \\
& +\beta_{t w} t \ln w+\beta_{t} t+\frac{1}{2} \beta_{t t} t^{2}+\beta_{Y t} t \ln Y
\end{aligned}
$$

\footnotetext{
${ }^{8}$ In equilibrium, mining firms spend as much on developing new deposits at the margin as the expected value of the resulting addition to the natural resource input, similar to the situation depicted for additions to the physical capital stock in Figure 2 above. Also, as with physical capital, we follow the convention of treating the flow of natural resource input as proportional to the underlying stock.

${ }^{9}$ For future work, it might be useful to also explicitly allow for depletion, the amount tied to the level of cumulative production, which may not be adequately captured by the depreciation measure in the stock of mineral and petroleum exploration capital.
} 
where $V C$ represents variable cost and all other variables are as defined previously, and the data used for these variables are listed in Appendix 1.

Differentiating (15) with respect to $\ln w$ yields

$$
\frac{\partial \ln V C}{\partial \ln w}=\beta_{w}+\beta_{w w} \ln w+\beta_{K w} \ln K+\beta_{R w} \ln R+\beta_{w Y} \ln Y+\beta_{t w} t
$$

Shephard's Lemma implies that $\partial V C / \partial w=L$, thus

$$
\frac{\partial \ln V C}{\partial \ln w}=\frac{w L}{V C}=1
$$

since labour is the only variable input in the short run in our specification.

Economic theory requires that the variable cost function is homogenous of degree 1 in variable input prices, given $K, R$ and $Y$. This implies that $\beta_{w}=1, \beta_{w w}=0, \beta_{K w}=0$, $\beta_{R w}=0$, and $\beta_{w Y}=0$. Combined with (16) and (17), the homogeneity condition gives rise to the following full set of restrictions

$$
\beta_{w}=1, \beta_{w w}=0, \beta_{K w}=0, \beta_{R w}=0, \beta_{w Y}=0, \beta_{t w}=0
$$

Applying the above restrictions, the translog cost function (15) can be simplified to

$$
\begin{aligned}
\ln V C= & \beta_{0}+\ln w+\beta_{Y} \ln Y+\beta_{R} \ln R+\beta_{K} \ln K \\
& +\frac{1}{2}\left[\beta_{K K}(\ln K)^{2}+\beta_{R R}(\ln R)^{2}+\beta_{Y Y}(\ln Y)^{2}\right] \\
& +\beta_{K R} \ln K \ln R+\beta_{K Y} \ln K \ln Y+\beta_{R Y} \ln R \ln Y \\
& +\beta_{t} t+\frac{1}{2} \beta_{t t} t^{2}+\beta_{Y t} t \ln Y
\end{aligned}
$$

Although this reduces the number of coefficients that need to be estimated from 19 to 12 , it is still large relative to the available sample size. As a further necessary step, the equilibrium condition of competitive output pricing behaviour is imposed. Together with the restrictions contained in (18), we can derive an inverse share equation of the form 


$$
\frac{1}{S_{L}}=\beta_{Y}+\beta_{Y Y} \ln Y+\beta_{K Y} \ln K+\beta_{R Y} \ln R+\beta_{Y t} t
$$

Appending the error terms to (20) and (19), the relevant coefficients can be estimated using this two-equation system with more precision than using (19) alone.

\subsection{Data and variable constructions}

The sample used to estimate the parameters in (19) and (20) is between 1974-75 and 2007-08. ${ }^{10}$ Appendix 1 contains a summary of the data sources and outlines how the variables are constructed.

\subsection{Results}

A popular technique to estimate a system of equations in applied econometrics is to use the Seemingly Unrelated Regression (SUR). ${ }^{11}$ This estimation procedure produces more efficient estimates of parameters than OLS when the errors across the equations in the system are contemporaneously correlated. SUR is used to estimate the coefficients in equations (19) and (20).

As a common practice, the errors associated with the two equations are assumed to be multivariate normally distributed. The iterative SUR function is used to estimate the coefficients. The parameter estimates using the iterative SUR are numerically equivalent to those of the maximum likelihood estimation (Berndt 1991).

Like many other studies that estimate the translog cost function, the possible non-stationarity in the data is assumed to be unimportant, particularly given the lack of power for the unit root tests in a small sample. The main purpose here is to obtain some plausible estimates of the

\footnotetext{
${ }^{10}$ The estimation could also be based on a larger sample size that includes additional data from 2008-09 to 2010-11. However, these results are less reliable due to the effects of the Global Financial Crisis (GFC) on the mining industry, which created some major structural break in the data. Thus, the smaller sample between 1974-75 and 2007-08 is used in this paper. The results based on the larger sample are available on request.

${ }^{11}$ Many original references on SUR, together with the early applied studies using this method are given in Berndt (1991).
} 
relevant coefficients for carrying out the decomposition exercise. Furthermore, as the time index has been included in the system, this is appropriate for estimating a trend-stationary process. If the data are indeed non-stationary, the log-level relationships could be seen as some long-run conditions that are based on producer's optimal behaviour in the equilibrium states. While the variable cost function relates to short-run behaviour by construction, (20) is based on the equilibrium condition that imposes competitive output pricing behaviour.

Experiments are conducted with using various lags for capital services and resource inputs in order to take account of the long lead time from the investment in capital goods to their use in production. It turns out that it is appropriate to lag both capital variables by one year in the empirical variable cost function.

The estimation results are presented in Table $1 .{ }^{12}$ The adjusted R-squared for the variable cost function (19) is 0.94 and for the equilibrium condition (20) is 0.83 . The values of Durbin-Watson statistic are 2.18 for (19) and 1.33 for (20). This indicates that autocorrelation is not a serious issue, although its presence would not bias the estimates.

\footnotetext{
12 The detailed estimation output is available on request.
} 
Table 1: Estimation results for the restricted translog variable cost function

\begin{tabular}{lllll}
\hline Parameter & Estimate & Standard error & $t$-statistic & probability \\
\hline$\beta_{0}$ & 0.294 & 0.174 & 1.692 & 0.097 \\
$\beta_{K}$ & -2.609 & 2.942 & -0.887 & 0.379 \\
$\beta_{R}$ & 6.309 & 1.967 & 3.207 & 0.002 \\
$\beta_{Y}$ & 4.203 & 0.278 & 15.104 & 0.000 \\
$\beta_{K K}$ & 0.216 & 2.748 & 0.079 & 0.938 \\
$\beta_{R R}$ & -7.009 & 7.411 & -0.946 & 0.349 \\
$\beta_{K R}$ & -5.324 & 4.828 & -1.103 & 0.275 \\
$\beta_{K Y}$ & 7.759 & 1.554 & 4.994 & 0.000 \\
$\beta_{R Y}$ & -3.546 & 0.531 & -6.677 & 0.000 \\
$\beta_{t}$ & -0.148 & 0.059 & -2.516 & 0.015 \\
$\beta_{t t}$ & 0.012 & 0.004 & 2.989 & 0.004 \\
$\beta_{Y t}$ & -0.234 & 0.074 & -3.173 & 0.003 \\
$\beta_{Y Y}$ & 0.513 & 0.625 & 0.822 & 0.415 \\
\hline
\end{tabular}

The estimated elasticity of variable cost with respect to resource inputs, $\beta_{R}$ is large and significantly different from zero, indicating the importance of resource inputs in mining production. Note that the coefficients for several variables in Table 1 are statistically insignificant. However, a test that all these coefficients are jointly zero is strongly rejected.

The requirements for a well behaved cost function include that it is non-decreasing and concave in input prices. A non-decreasing cost function implies that the first derivative of a cost function with respect to each input price must be non-negative. As the variable cost function in our case only contains one variable input, that is labour, this requirement is satisfied by the imposed restriction, $\beta_{w}=1$. Concavity of the cost function in input prices requires that the matrix of substitution elasticities be negative semi-definite. Again, due to the single variable input in our variable cost function of (15), this requirement is trivially satisfied.

The dual measure of technical change, $-\varepsilon_{C, t}$ and the inverse of the returns to scale, $\varepsilon_{C, Y}$ along with their standard errors can be calculated using the above estimation outputs. The results based on the sample mean are shown in Table 2. 
Table 2: Estimates of technological change and inverse of returns to scale ${ }^{13}$

\begin{tabular}{|l|l|l|}
\hline & Dual measure of technical change & Inverse of returns to scale \\
& $-\varepsilon_{C, t}$ & $\varepsilon_{C, Y}$ \\
\hline Estimate & 0.020 & 1.078 \\
\hline Standard error & 0.011 & 0.024 \\
\hline
\end{tabular}

The above results imply that the average of the 'true' rate of technological change in Australian mining is about $2.0 \%$ per annum between $1974-75$ and 2007-08. The returns to scale elasticity is $0.94(\approx 1 / 1.078)$, indicating a moderate level of decreasing returns to scale. ${ }^{14}$ Based on the same sample period as in this study, Topp et. al. (2008) estimate that the average annual MFP growth in Australian mining is $2.5 \%$ with depletion effects removed, and $2.3 \%$ with the removal of depletion effects as well as adjusting for investment lags in capital services. Either of these estimates is well within one standard error of the estimate of the dual rate of technical change in Table 2, so the parametric approach employed here can be considered as an equivalent method to achieving a plausible correction to measured productivity growth for the Australian mining sector. ${ }^{15}$

Despite the fact that various coefficients and variables are involved in estimating the dual measure of technical change and returns to scale, the estimates for the two measures seem plausible, and are quite stable over the sample period. This is shown in Table $3 .^{16}$

\footnotetext{
${ }^{13}$ As these estimates may not be normally distributed, the standard significance test using the t-statistic may not be applicable in this case.

${ }^{14}$ The estimate of slightly decreasing returns to scale may be taken to be a reflection of the natural constraints to expansion of natural resource production. Expansion of resource capital (as measured by exploration investment), along with physical capital and labour does not yield proportional increases in output when the easiest deposits have been discovered first.

${ }^{15}$ Instead of adjusting quantities of inputs as in Topp, et al (2008), our approach adjusts the costs of production associated with short-run fixity of physical capital and resource inputs as well as non-constant returns to scale and the absence of a charge for the use of natural resource inputs in the conventional productivity growth accounting.

${ }^{16}$ However, the estimated coefficients for the translog variable cost function are sensitive to the changes in specifications. This problem may be caused by the lack of degrees of freedom in the estimation, which is typically encountered in the estimation of the translog form using low frequency data.
} 
Table 3: Annual estimates of the 'true' technical change and returns to scale

\begin{tabular}{|c|c|c|}
\hline & Dual measure of technical change (\%) & Returns to scale \\
\hline $1974-75$ & 4.3 & 0.787 \\
\hline $1975-76$ & 3.4 & 0.881 \\
\hline 1976-77 & 3.4 & 0.971 \\
\hline 1977-78 & 3.1 & 0.970 \\
\hline $1978-79$ & 2.8 & 1.017 \\
\hline $1979-80$ & 2.3 & 1.108 \\
\hline $1980-81$ & 2.4 & 0.925 \\
\hline $1981-82$ & 1.9 & 0.857 \\
\hline 1982-83 & 1.8 & 0.823 \\
\hline 1983-84 & 1.7 & 0.957 \\
\hline 1984-85 & 2.2 & 1.067 \\
\hline $1985-86$ & 2.7 & 0.991 \\
\hline 1986-87 & 1.9 & 0.923 \\
\hline 1987-88 & 2.5 & 0.957 \\
\hline 1988-89 & 2.7 & 0.892 \\
\hline $1989-90$ & 2.9 & 0.896 \\
\hline $1990-91$ & 2.6 & 0.985 \\
\hline 1991-92 & 2.6 & 0.997 \\
\hline $1992-93$ & 2.2 & 1.001 \\
\hline 1993-94 & 2.2 & 0.918 \\
\hline 1994-95 & 2.2 & 0.952 \\
\hline $1995-96$ & 2.4 & 0.914 \\
\hline $1996-97$ & 2.2 & 0.844 \\
\hline 1997-98 & 1.9 & 0.843 \\
\hline 1998-99 & 1.6 & 0.811 \\
\hline $1999-00$ & 1.4 & 0.958 \\
\hline $2000-01$ & 1.3 & 1.155 \\
\hline $2001-02$ & 1.2 & 1.046 \\
\hline $2002-03$ & 1.0 & 0.931 \\
\hline 2003-04 & 0.6 & 0.828 \\
\hline 2004-05 & 0.6 & 0.840 \\
\hline $2005-06$ & 0.3 & 0.933 \\
\hline $2006-07$ & 0.3 & 0.965 \\
\hline 2007-08 & 0.4 & 0.852 \\
\hline Average & 2.0 & 0.938 \\
\hline
\end{tabular}

The difference between the 'true' and measured MFP growth constitutes the error that can be attributed to various factors. Equation (14) decomposes the measured MFP growth into four major components, namely, the 'true' MFP growth, $-\varepsilon_{C, t}$; the component reflecting scale effect, $\left(1-\varepsilon_{C, Y}\right)\left[\frac{S_{L}}{\varepsilon_{C, Y}}(\hat{K}-\hat{L})+\hat{Y}\right]$, the capital utilisation component, $\left(S_{K}^{*}-S_{K}\right) \hat{K}$, and the remaining component capturing the effect of resource inputs, $\left(S_{R}^{*}-S_{R}\right) \hat{R}+S_{R}(\hat{R}-\hat{K})$, 
which is derived residually. The decomposition results using the sample average values of the variables, including shadow prices calculated from coefficients in Table 1, are shown in Table 4.

Table 4: Decomposition of measured MFP (evaluated at the sample mean)

\begin{tabular}{|c|l|c|l|l|}
\hline $\begin{array}{l}\text { Measured } \\
\text { MFP growth }\end{array}$ & $\begin{array}{l}\text { MFP growth } \\
\text { based on the dual } \\
\text { measure }\end{array}$ & Scale effect & $\begin{array}{l}\text { Capital utilisation } \\
\text { effect (physical } \\
\text { capital only) }\end{array}$ & $\begin{array}{l}\text { Resource } \\
\text { input effect }\end{array}$ \\
\hline-0.0023 & 0.0203 & -0.0020 & -0.0139 & -0.0066 \\
\hline
\end{tabular}

All three components aside from the 'true' MFP growth - scale effect, capacity utilisation effect and resource input effect - are negative, thus reducing measured MFP growth below the 'true' MFP growth. The negative scale effect is due to the presence of a moderate level of decreasing returns to scale. The negative capital utilisation effect is the largest in absolute value, reflecting periods of substantial deviations from long-run equilibrium in Australian mining and over-capacity production in the recent boom years followed by years of low utilisation of capacity in the 1980s and 90s. As shown in Figure 2, production either above or below capacity leads to higher cost reflecting lower productivity. The resource inputs effect is also large. As discussed above, the resource input effect is a combination of the effects due to its quasi-fixity relative to physical capital and the fact that natural resource inputs are excluded from measured MFP (as missing inputs).

The finding that missing resource inputs contribute negatively to measured MFP growth is not surprising. Because the implied price of natural resource inputs in measured MFP growth is zero, there is a negative contribution to measured MFP growth whenever there is depletion of the resource input. The negative effect is further enlarged whenever the growth in the resource input is below the growth of physical capital, as the share of capital in the conventional growth accounting is a residual and therefore implicitly includes the 
contribution of the unmeasured resource inputs. These negative effects have been a particular feature of the recent mining boom, as exploration capital has failed to keep up with either output growth or physical capital growth. Hence, there has been negative growth in measured MFP according to ABS statistics as compared to the positive estimated "true" MFP growth shown in Table 4.

This negative contribution of the resource input to measured MFP is also consistent with the findings in other studies, which show a negative relationship between measured MFP and resource inputs, whether the latter is measured by a yield index in the case of Topp et. al. (2008), or captured by the cumulative output as in Young (1991) and Rodriguez and Arias (2008). The main difference from the Topp et. al. and Young methods is that their adjustments are based on altering the measured quantity of inputs as appropriate for a primal production approach, whereas our methods and those of Rodriguez and Arias are based on adjusting for the value of resources used up in production as appropriate for a dual cost approach.

\section{Conclusions}

This paper investigates the main causes for the Australian mining industry's deteriorating productivity performance as measured by the conventional MFP index during the recent mining boom. It has long been known in the literature that the measure of productivity change in extraction industries can be affected by the evolution of natural resource inputs. This has provided some useful clues to our investigation of the recent experience of rising production and falling productivity in Australian mining. It points to some underlying issues associated with the measurement of MFP growth in mining, which we address by first deriving a relationship between the measured and 'true' MFP growth that separates the effects of returns to scale, capacity utilisation and resource inputs on measured MFP. A 
translog variable cost function is then estimated that provides the parameter estimates for the various components in the decomposition formula.

The results show that the average MFP growth in Australian mining based on the dual measure of technical change over the sample period is $2 \%$, rather than $-0.2 \%$ from the published index. Also, the model-based MFP growth has been relatively stable compared to the large swings observed in the official mining MFP statistics. Our results indicate that failure to account for natural resource inputs has lowered the measured MFP growth, while capacity utilisation and returns to scale also have large negative impacts on measured MFP during the sample period.

As is known, measured MFP growth reflects not only technological progress, but also nonconstant returns to scale, efficiency changes, variations in capacity utilisation and measurement errors. The results in this paper are concrete examples for this statement. More importantly, they highlight the concern that focusing on measured MFP alone can misinform us about the direction and magnitude of efficiency and technical changes in the mining industry. Consequently, caution should be exercised in using the MFP estimates based on the conventional measure. Particularly, great care has to be taken in using these estimates in making policy decisions for the mining industry.

\section{References}

Australian Bureau of Statistics (2011), Experimental Estimates of Industry Multifactor Productivity, Australia: Detailed Productivity Estimates, ABS Cat. No. 5260.0.55.002.

Azzalini, Paul, Bloch, Harry and Haslehurst, Puala (2007), 'Australian coal mining: estimating technical change and resource rents in a translog cost function' in Conference Proceedings of the 30th Conference of the International Association for Energy Economics, edited by School of Economics and Finance, Victoria University, Wellington, New Zealand: Oceania Association for Energy Economics. 
Berndt, Ernst R. (1991), The Practice of Econometrics: Classic and Contemporary, Addison Wesley Publishing Company, Reading MA.

Berndt, Ernst R. and Fuss Melvyn A. (1986), 'Productivity measurement with adjustments for variations in capacity utilization and other forms of temporary equilibrium', Journal of Econometrics, 33, pp. 7-29.

Bloch, Harry (2010), 'A tale of two cities: Cyclical movements in price and productivity in mining and manufacturing' in Gregory K. Dow, Andrew Eckert and Douglas S. West, editors, Industrial Organization, Trade and Social Interaction, University of Toronto Press, Toronto, pp. 160-180.

Diewert, W.E. and K.J. Fox (2008), 'On the estimation of returns to scale, technical progress and monopolistic markups', Journal of Econometrics, 145, pp. 174-93.

Hall, Robert E. (1988), 'The relation between price and marginal cost in U.S. industry', Journal of Political Economy, 96(5), pp. 921-47.

Hotelling, H. (1931), 'The economics of exhaustible resources', Journal of Political Economy, 39, pp. 137-75.

Hulten, Charles R. (1986), 'Productivity change, capacity utilisation, and the sources of efficiency growth', Journal of Econometrics, 33, pp. 31-50.

Lasserre, P. and Ouellette, P. (1988), 'On measuring and comparing total factor productivities in extractive and non-extractive sectors', Canadian Journal of Economics, 21(4), pp. 826834.

Morrison Paul, C. (1999), Cost Structure and the Measurement of Economic Performance: productivity, utilization, cost economies and related performance indicators, Kluwer Academic Press, Amsterdam.

Morrison, C. and Schwartz, A. (1994), 'Distinguishing external from internal scale effects: the case of public infrastructure', Journal of Productivity analysis, 5(3), pp. 249-70.

Morrison, C. and Schwartz, A. (1996), 'Sate infrastructure and productive performance', American Economic Review, 86(5), pp. 1095-111.

OECD (2001), OECD Productivity Manual: A Guide to the Measurement of Industry-level and Aggregate Productivity Growth, OECD. 
Ohat, M. (1974), 'A note on the duality between production and cost functions: rate of returns to scale and rate of technical progress', Economic Studies Quarterly, 25(3), pp. 63-5.

Rodriguez, X.A., and Arias, C. (2008), 'The effects of resource depletion on coal mining productivity', Energy Economics, vol. 30, pp. 397-408.

Topp, V., Soames, L., Parham, D. and Bloch, H. (2008), Productivity in the Mining Industry: Measurement and Interpretation, Productivity Commission Staff Working Paper, Australian Productivity Commission, Canberra.

Wedge, T.A. (1973), 'The effect of changing ore grade on the rates of change in the productivity of Canadian mining industries', The Canadian Mining and Metallurgical Bulletin, 66, pp. 64-66.

Young, D. (1991), 'Productivity and metal mining: evidence from copper-mining firms', Applied Economics, 23, pp. 1853-59.

Zheng, Simon and Bloch, Harry. 2010. Australia's Mining Productivity Paradox: Implications for MFP Measurement, Centre for Research in Applied Economics Working Paper Series: no. 201012, Curtin University, Perth, WA. 


\section{Appendix 1}

Table A1: Data sources and construction

\begin{tabular}{|c|c|c|}
\hline Variable & Source & Notes \\
\hline $\begin{array}{l}\text { Variable cost, } \\
V C\end{array}$ & $\begin{array}{l}\text { a) } 1989-90 \text { to 2006-07: ABS Cat. No. } 5204.0 \\
\text { Australian System of National Accounts, Table } 48 \text {. } \\
\text { Compensation of Employees, by Industry - Current } \\
\text { prices } \\
\text { b) } 1974-751988-89 \text { : ABS unpublished national } \\
\text { accounts data on total labour income from } \\
\text { incorporated and un-incorporated businesses }\end{array}$ & $\begin{array}{l}\text { The variable cost is just the } \\
\text { cost of obtaining labour } \\
\text { services. The data are } \\
\text { spliced to connect the two } \\
\text { periods and then indexed to } \\
1 \text { at the starting of the } \\
\text { sample period }\end{array}$ \\
\hline $\begin{array}{l}\text { Nominal wage } \\
\text { rate, } w\end{array}$ & $\begin{array}{l}\text { a) 1984-85 to 2006-07: ABS Cat. No. } 6302.0 \\
\text { Average Weekly Earnings, Australia, Table 10I. } \\
\text { Average Weekly Earnings, Industry, Australia } \\
\text { (Dollars) - Original - Persons, Total Earnings - } \\
\text { mining } \\
\text { b) } 1974-75 \text { to 1983-84: ABS Cat. No. 6350.0, } \\
\text { Average weekly earnings, Table } 5 \text { Full-time adult } \\
\text { non-managerial employees, average weekly } \\
\text { earnings, industry, Australia, at November 1974- } \\
1990 \text { (dollars) - persons - mining }\end{array}$ & $\begin{array}{l}\text { The earlier period data are } \\
\text { provided by ABS customer } \\
\text { service, as they are not } \\
\text { available on the ABS } \\
\text { website. The data are } \\
\text { spliced to connect the two } \\
\text { periods and then indexed to } \\
1 \text { at the starting of the } \\
\text { sample period }\end{array}$ \\
\hline $\begin{array}{l}\text { Conventional } \\
\text { capital services } \\
K\end{array}$ & $\begin{array}{l}\text { Productive capital stock by assets, chain volume } \\
\text { measure, excluding mineral and petroleum } \\
\text { exploration and the corresponding rental prices for } \\
\text { the different assets } \\
\text { a) } 1985-86 \text { to } 2006-07 \text {, ABS Cat. No. } \\
5260.0 .55 .002 \text { Experimental Estimates of Industry } \\
\text { Multifactor Productivity, Australia: Detailed } \\
\text { Productivity Estimates, Nov } 2009 \text {. } \\
\text { b) 1974-75 to 1984-85: ABS unpublished data on } \\
\text { productive capital stock by asset and the } \\
\text { corresponding data on rental prices }\end{array}$ & $\begin{array}{l}\text { Aggregation also includes } \\
\text { the assets from } \\
\text { unincorporated businesses. } \\
\text { Applying the Tornqvist } \\
\text { index for capital services } \\
\text { and the corresponding } \\
\text { weights that are based on the } \\
\text { rental prices. The index is } \\
\text { scaled to } 1 \text { at the starting of } \\
\text { the sample period }\end{array}$ \\
\hline $\begin{array}{l}\text { Proxy for } \\
\text { resource inputs: } \\
\text { mineral and } \\
\text { petroleum } \\
\text { exploration, } R\end{array}$ & $\begin{array}{l}\text { Productive capital stock for mineral and petroleum } \\
\text { exploration, chain volume measure } \\
\text { a) } 1985-86 \text { to } 2006-07 \text {, ABS Cat. No. } \\
5260.0 .55 .002 \text { Experimental Estimates of Industry } \\
\text { Multifactor Productivity, Australia: Detailed } \\
\text { Productivity Estimates, Nov } 2009 \\
\text { b) } 1974-75 \text { to } 1984-85 \text { : ABS unpublished data on } \\
\text { productive capital stock, chain volume measure }\end{array}$ & $\begin{array}{l}\text { Indexed to } 1 \text { at the starting } \\
\text { of the sample period }\end{array}$ \\
\hline $\begin{array}{l}\text { Volume of } \\
\text { output, } Y\end{array}$ & $\begin{array}{l}\text { Gross value added, Productivity Commission } \\
\text { productivity database, which is based on both } \\
\text { published and unpublished ABS data on the chain } \\
\text { volume index of gross value added }\end{array}$ & $\begin{array}{l}\text { Indexed to } 1 \text { at the starting } \\
\text { of the sample period }\end{array}$ \\
\hline
\end{tabular}

